\title{
NSF/NASA-GSFC MEMS EDUCATION WORKSHOP OUTCOMES
}

\author{
Beth L. Pruitt \\ Dept. of Mechanical Engineering \\ Stanford University \\ Stanford, CA USA, pruitt@stanford.edu \\ Reza Ghodssi \\ Dept. of Electrical and Computer Engineering \\ University of Maryland \\ College Park, MD, USA \\ Jack W. Judy \\ Dept. of Electrical Engineering \\ University of California \\ Los Angeles, CA, USA
}

\begin{abstract}
The first North American workshop on MEMS Education was held on January 30, 2005 in Miami, Florida before the MEMS 2005 conference. The purpose of the workshop was to gather a diverse audience including MEMS academics, professionals from MEMS industry, leaders from MEMS-relevant U.S. government agencies, as well as current students. Goals included: identifying 'best practices' to share across organizations teaching MEMS courses; identifying cross-cutting issues and a set of recommendations to sponsor organizations for investment in MEMS educational development; and establishing an open dialog on these issues for continued interactions. Challenges identified include: developing a curriculum meeting needs of students seeking to be educated in this field; suitably spanning the broad interdisciplinary space covered by MEMS; and creating a technically prepared workforce.
\end{abstract}

\section{INTRODUCTION}

MEMS as a field has matured to the point where successful 'MEMS-enabled' products are on the market and require engineering support of the total product lifecycle. Universities increasingly need to consider the growing requirement for more MEMS trained students at all degree levels as well as how to prepare graduates to work in the integrated product and process development environment required for MEMS manufacturing. Academically and industrially, increasingly cross-disciplinary skills are required as are microfabricated tools to interface with nanoscale devices and biological materials. MEMS constitutes substantial research and teaching activities at universities, and the requirements for systems level integration of design, process \& test offer unique educational challenges and opportunities. Challenges lie in developing curricula which are: 1) suited to the needs of students seeking to work in MEMS or to apply MEMS to new disciplines, 2) span the broad interdisciplinary space covered by MEMS device design, 3) address the broad cross-disciplinary applications for microdevices, and most importantly, 4) create a technically prepared workforce at the BS, MS, and PhD level.

This paper reports on outcomes from the first workshop on MEMS Education held in January 2005 in Miami, Fl as well as data from a set of surveys of the North American MEMS community [1]. The opportunity exists to incorporate MEMS into

\author{
M. Taher A. Saif \\ Dept. of Mechanical Engineering \\ University of Illinois \\ Urbana-Champagne, IL, USA
}

\author{
Kimberly L. Turner \\ Dept. of Mechanical Engineering \\ University of California \\ Santa Barbara, CA, USA
}

\author{
Martin A. Schmidt \\ Dept. of Electrical Engineering \\ Massachusetts Institute of Technology \\ Cambridge, MA, USA
}

mainstream engineering education and to consider if it should be used as a vehicle to effect change in engineering curricula [2-3].

A small group of academics attending the Hilton Head '04 meeting met informally to discuss the educational practices at their respective universities. This group discussed common experiences, shared their problems, and observed that while most schools had developed MEMS courses, few texts existed and very little sharing between programs had occurred. The outcome of this discussion was to plan and deliver a meeting on MEMS Education. A committee comprised of the authors of this paper secured funding and organized a one day workshop following MEMS2005. The workshop was sponsored by the National Science Foundation (NSF) and the National Aeronautics and Space Administration Goddard Space Flight Center (NASA-GSFC).

The goals of the workshop were to:

- Ground participants in the history of MEMS education

- Assess the current status of MEMS Education

- Hear from industry on their educational/hiring needs

- Hear from funding agents on future areas of research funding

- Provide ample discussion time to

- assess the current status of educational programs

- identify what's working and what's not

- pinpoint opportunities to develop/share/collaborate (especially items perceived as 'low hanging fruit')

- Draw conclusions and make recommendations for

- organization of subsequent workshops/conferences

- funding agency initiatives aimed at supporting education

- industry groups with an interest in advocating or supporting MEMS education initiatives

- Create a web site with all materials collected before and at the workshop (http://MEMSED.stanford.edu).

\section{PRELIMINARY SURVEYS}

Prior to the workshop, the committee sought input from educators, employers and students on their perceptions of the strengths and weaknesses in MEMS education. Educators were also asked to share summaries of the courses and programs at their universities. Three separate online surveys for MEMS Education Instructors, Industry, or Students were developed and participation of the North American MEMS community was requested by 


\begin{tabular}{|c|c|c|c|c|c|c|c|c|c|c|}
\hline $\begin{array}{l}\text { MEMS fab. } \\
\text { lecture }\end{array}$ & $\begin{array}{l}\text { MEMS } \\
\text { fab. lab }\end{array}$ & $\begin{array}{l}\text { MEMS } \\
\text { Science }\end{array}$ & $\begin{array}{c}\text { MEMS } \\
\text { Technology }\end{array}$ & $\begin{array}{c}\text { MEMS } \\
\text { Design }\end{array}$ & $\begin{array}{l}\text { Nanofab } \\
\text { lecture }\end{array}$ & $\begin{array}{c}\text { Nanofab } \\
\text { lab }\end{array}$ & $\begin{array}{l}\text { Nano- } \\
\text { science }\end{array}$ & $\begin{array}{l}\text { Micro- } \\
\text { fluidics }\end{array}$ & $\begin{array}{c}\text { Bio- } \\
\text { MEMS }\end{array}$ & Other \\
\hline $67 \%$ & $43 \%$ & $46.8 \%$ & $30 \%$ & $62.5 \%$ & $30 \%$ & $7.8 \%$ & $28 \%$ & $25 \%$ & $34 \%$ & $43 \%$ \\
\hline
\end{tabular}

Table 1: Courses offered by universities surveyed.

emails to over 2000 previous MEMS-related conference participants.

\section{Instructor Survey}

This survey garnered 64 responses from 34 different institutions in 3 countries. Faculty were asked what types of courses are taught at their universities and at what level they are taught. The types of courses are summarized in Table 1; most universities have lecture based courses on design and fabrication and fewer than half report some kind of lab courses. The target audience of the courses is shown in Figure 1; very few institutions offer separate courses targeted to undergraduates, though most offer mixed level courses accessible to undergraduates. The average class size varied greatly, and for lab courses, the costs and difficulty of processing (gauged by number of masks) also varied significantly. All institutions with labs reported a mix of support from industry, institution and investigator sponsored research projects. From this, one may infer that institutional commitment and partnerships with industry are indicators of successful courses providing hands-on experience.

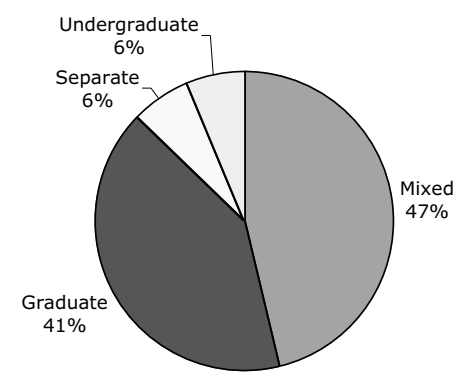

For lab courses only:

-Average \# of Students: 32

(s.d. 29, significant variation)

-Average Masks per class: $\mathbf{5}$ (varies from 1-12)

-Average Cost per Student: $\$ 1829$

(significant variation) -Sponsorship: mix of Industry, Institutional, and PI support.

Figure 1. Intended audience of courses taught.

Mixed grad/undergrad was the most common course level. 100\% of respondents have a microfab on campus, though only $69 \%$ of fabrication courses have students do their own processing, and $45 \%$ have an instructional fab.

Faculty were also asked about cooperation in teaching and developing courses. More than a quarter reported 'a lot' of cooperation amongst MEMS faculty at their institution, 60\% felt there was some cooperation, the rest report little to no cooperation.

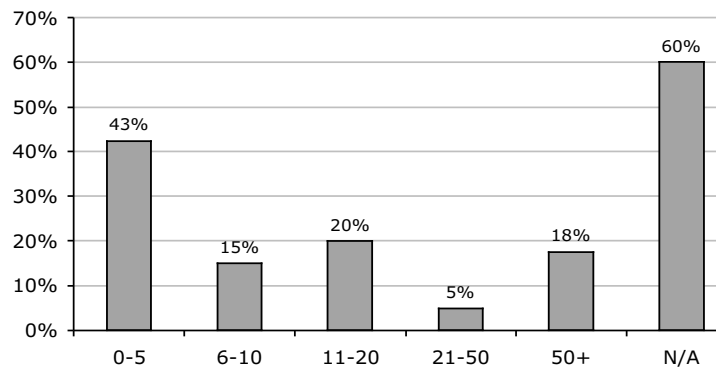

Figure 2. MEMS PhDs granted. Faculty estimates of MEMS related $P h D s$ graduated from their institutions in the last 10 years.

Faculty estimated the number of $\mathrm{PhDs}$ specializing in MEMS graduating from their institutions, Figure 2. Only the largest estimate from each institution was used. Averaging the bins, as many as 600 MEMS trained PhDs have graduated from the responding institutions in the last 10 years. This is consistent with industry estimates of hiring.
Respondents described successful pedagogical methods; the most frequently cited included:

- Hands on Experience

- Model Based Teaching

- Physics of processes rather than recipes.

- Design Projects with hands-on component

- Deploying real problems and utilizing "coaches" from industry

- Comparing to macro-scale sensors to show benefits and drawbacks to scaling.

For practical design training and analysis, educators used a variety of software tools, including Intellisuite, SUGAR, ANSYS, Co-Solve, ADS, and FEMLAB. Several schools reported fabrication and characterization of real devices using foundries; $21 \%$ use foundry services for classes, e.g. MUMPS/CRONOS, University of Michigan, and UC Berkeley Internal.

From their educational experience, MEMS educators perceive the most important skills their students take away include: concepts of miniaturization and scaling laws; hands-on fabrication experience; and the ability to think of the big picture and be interdisciplinary. Some educators felt students need to obtain strength in fundamental areas then layer MEMS knowledge on that fundamental knowledge; two respondents felt MEMS was just a repackaging of traditional disciplines. Educators were also asked how well prepared their graduates are. With one exception, most respondents felt they were very well prepared. Educators estimated more than half their MEMS trained graduates go to Industry, while $20 \%-30 \%$ go to Academia including faculty \& postdocs, and about $10 \%$ go to National Laboratories. This is fairly consistent with industry and student survey results.

\section{Industry Survey}

The participants of this survey included 36 industrial affiliates and 6 national laboratories. Figure 3 tabulates estimates of 76 industrial survey participants on the number of graduates with MEMS educational training hired into their organization in the past 10 years. Notably, Analog Devices, Sandia National Laboratory, Robert Bosch, and Rockwell Scientific respondents estimate they have hired more than 20 MEMS graduates at all degree levels in the last 10 years. From responses to employer surveys, one may infer that the MEMS related employers responding to the survey hired more than $60 \%$ of MEMS PhDs produced in North America over that 10 year period.

Number of employers estimating scale of MEMS

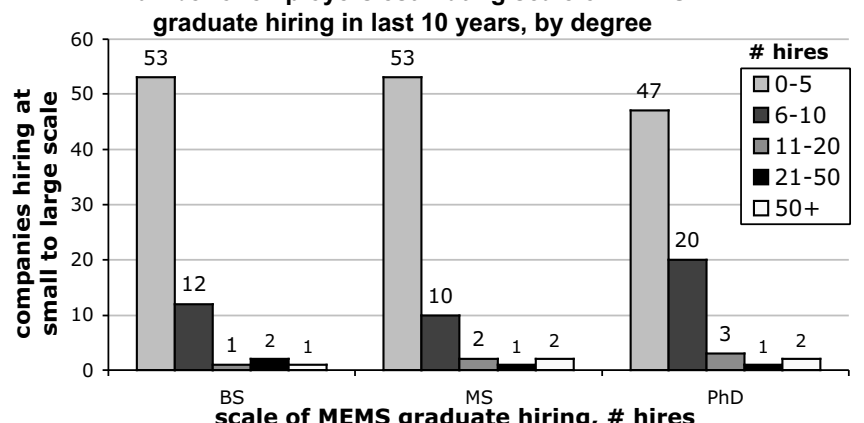

Figure 3. Industry hiring estimates for the past 10 years, by highest degree. Averaging the bins, as many as 330 BS, 350 MS and $430 \mathrm{PhDs}$ have been hired. 


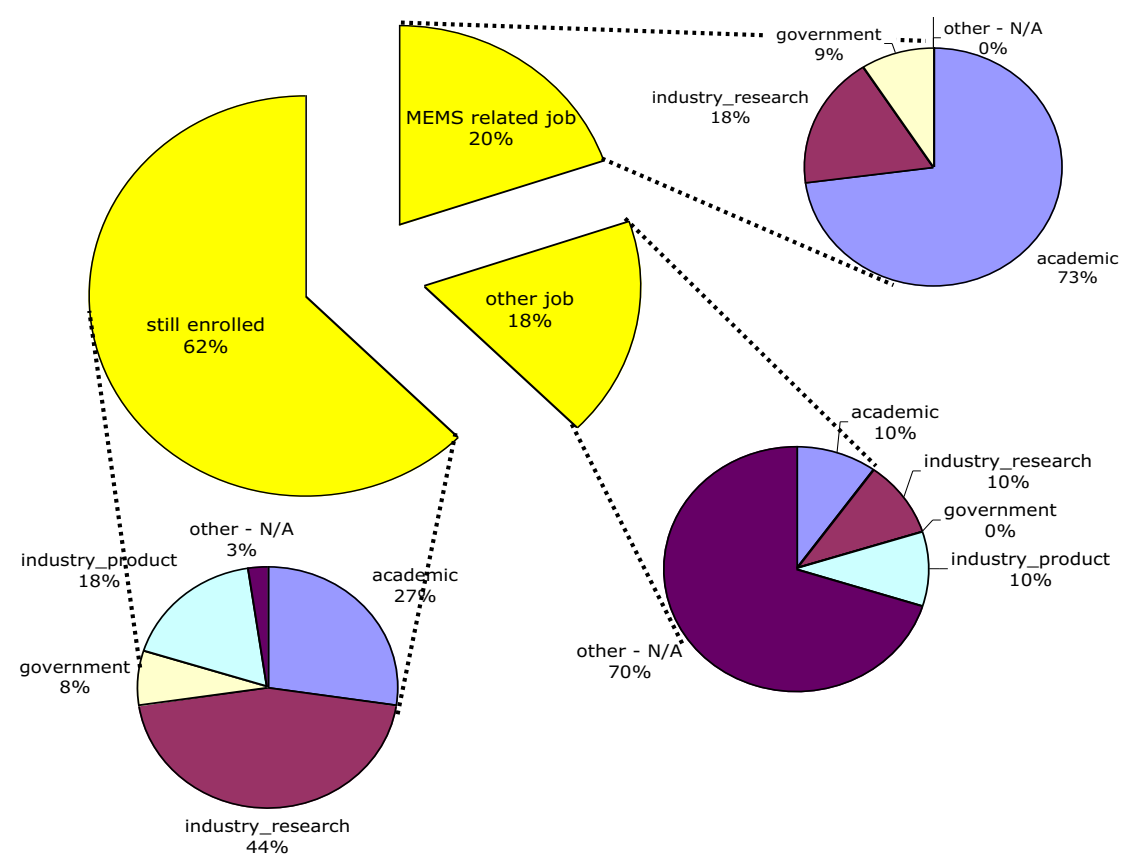

Figure 4. MEMS Student Employment. Of those still enrolled, most expect to do research in industry, of those already working in MEMS related jobs, most are in academics. The majority of those employed in other jobs do not report affiliation with product development or research; only two are academics in fields other than MEMS.

Industry participants answered the question, "How well prepared to succeed were the MEMS graduates you have hired?" Overall, industry members were most pleased with the level of preparation afforded by some graduate work (Figure 5).

When asked to list the most valuable skills/assets that MEMS graduates possess, the dominant themes were the multidisciplinary background and hands-on experience with microfabrication and testing/characterization. Conversely, the most common missing skill/asset repeatedly emphasized was a need for a "reality check." Many respondents commented that employees were naïve regarding manufacturing, packaging and reliability concerns, and lacked a basic business understanding. Generally poor writing and communication skills were also cited numerous times. However, $74 \%$ did indicate a willingness to work with MEMS educators to ensure that MEMS graduates have an opportunity to learn these commonly missing skills.

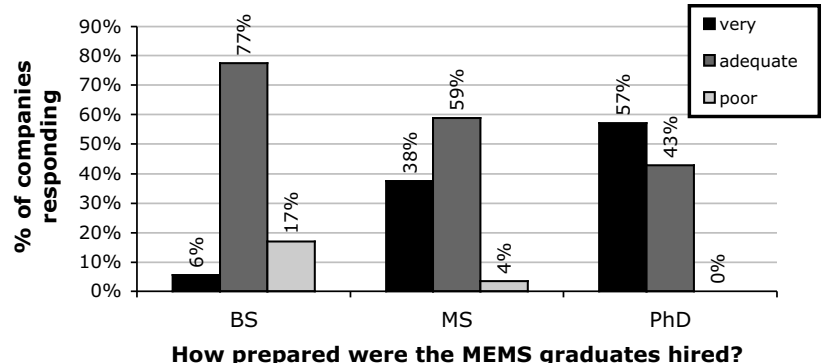

Figure 5. Industry assessment of the preparation of MEMS graduates hired, by degree level. Employers were generally most satisfied with preparation of PhDs hired for MEMS positions.

\section{Student Survey}

Fifty-six current or recent students participated in this survey, most respondents were $\mathrm{PhD}$ candidates. Their majors were $40 \%$ Electrical Engineering, 42\% Mechanical Engineering and a mix of other disciplines. Students reported on their current or expected jobs (Figure 4) and most were optimistic about obtaining research jobs in industry. About $60 \%$ of the students want industrial jobs

and $30 \%$ want academic jobs after graduation. Almost $90 \%$ of students felt they would get MEMS related jobs after graduation.

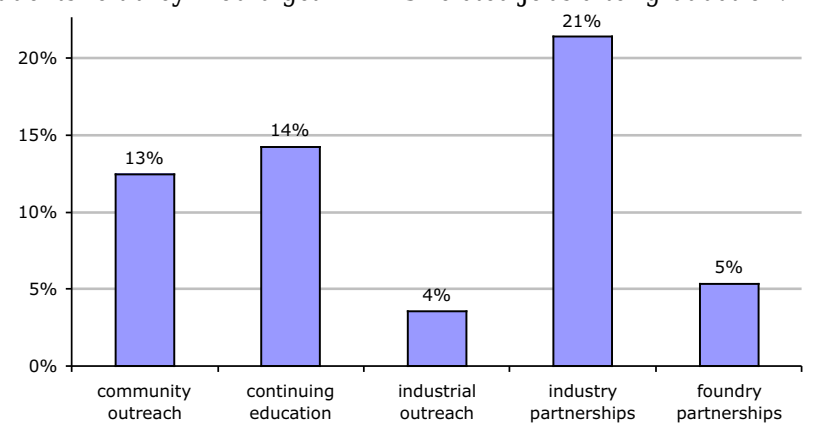

Figure 6. Student reported experience with forms of industrial or community outreach related to MEMS

Most students felt they should have at least an MS degree to be successful in a MEMS related career but they perceived increased preparation with a PhD (Figure 5).

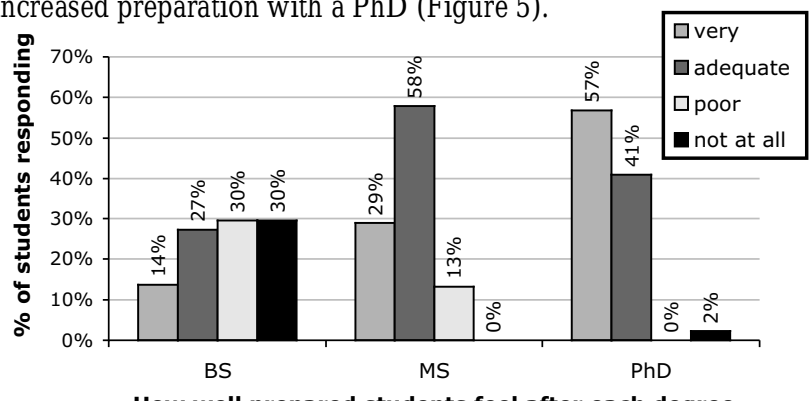

How well prepared students feel after each degree

Figure 7. Student self-perception of preparation for MEMS careers also increases with advanced degrees.

This is consistent with industry perceptions. Students were also asked about their involvement or collaboration with programs outside of their university. Several students reported experience with forms of industrial or community outreach related to MEMS (Figure 6); however, the exposure to non-academic partners should 
be higher given industry interest in improving MEMS education.

The students identified (1) hands on MEMS fabrication training, (2) broad fundamental science, and (3) MEMS design as the most important learning activities in a MEMS curriculum. Similarly, they felt that the breadth of knowledge base fabrication, design, basic physics of MEMS, materials science of MEMS materials, and analysis techniques are the most valuable skills/assets that they will bring to their employers.

\section{THE WORKSHOP}

Common issues and themes submitted by participants in advance of the workshop centered on: interdisciplinary education; integration with the undergraduate engineering curricula; funding practical MEMS experiences; and keeping MEMS education current with industry needs. Challenges cited included:

- Today's market and product development environment require BS level graduates to think across their disciplines and have a deep appreciation of the interplay between different but concurrent physical, chemical and biological effects. How do we integrate MEMS into BS level engineering education?

- Promoting interdisciplinary education

- Challenges of making MEMS education cost effective

- Addressing the breadth and depth of current and future directions for MEMS curricula, especially as it relates to the manufacturability of MEMS devices

- Developing comprehensive programs, e.g. a series of courses with central themes rather than scattered special topics

The workshop included panel presentations by industry and funding agents, summaries of the survey results, and ample time for discussion. The content presented and generated at the workshop, as well as that submitted to the committee, and links to MEMS courses at participating universities may be found at: http://MEMSED.stanford.edu/. The final agenda and presentation slides (where available) are also included on the site.

\section{Panel discussions}

The industry panel (Cleo Cabuz of Honeywell and MEMS Industry Group, Richard Payne of Polychromix, and Michael Judy of Analog Devices) and associated discussion covered several major themes including the optimum curriculum balance for a MEMS engineer. Specifically, the preference for students trained in MEMS or trained in a traditional field with a focus on MEMS? Overall, the group favored the latter, but recognized that there was a challenge in teaching all the perceived important skills in a finite degree program. There was concern about certain 'practical' elements of MEMS being taught. These include packaging, product design, reliability, failure analysis, statistical analysis, and patents. Various panel members pointed to other fields (e.g. Aeronautics) that are successful in incorporating some of the themes. It was also pointed out that a lack of industry standards hampered this effort.

Means of engaging industry in the education process were discussed, including 'certification' processes for MEMS courses/degrees or continuing education certificate programs. There was also discussion of specific skills and classes. There was general recognition that fabrication classes are well done, but that as the fabrication becomes more standardized, more emphasis is needed on design and test.

The funding agent panel (Rajinder Khosla of NSF, Clark Nguyen of DARPA, Carl Stahle of NASA-GSFC) and the ensuing discussion focused on issues related to the types of funding and methods for collaboration and research between industry and academia. Emphasis was made that industry pursues research only to the level of solving emergent problems as they do not have the luxury of time and money to explore fundamentals beyond what their product demands. A comparison of the funding agencies and their missions highlighted that DARPA is deadline and product driven first and research programs must have benefit to DOD to be funded; NSF grants and fellowships are the most common method of supporting students and basic research and also provide the most flexibility in creativity in research while requiring evolution of education; NASA is specifically interested in building products that their enable space exploration but have found that jointly mentored student course and research projects are a good model for technology development and transfer in MEMS. On the education side, industrial/national laboratory affiliates like NASA are willing to provide real research problems with short term funding as well as student internships.

\section{Breakout groups and discussion}

In the afternoon, participants were encouraged to join one of five group discussions. The discussion groups were asked to debate recommendations which they would make to various groups having an interest in MEMS Education (Academics, Industry Groups, Funding Agents, Conference Organizers, Publishers, Media, K-12 Specialists). The specific recommendations of each group are contained in the Power Point Presentation slides collected at the meeting and are found on the workshop website.

\section{CONCLUSIONS AND FUTURE DIRECTIONS}

Several recommendations emerged from the workshop. The first two have been accomplished but require maintenance, and the profile of the remaining issues has already been elevated to discussion among faculty, in industry working groups, and at NSF.

1. Establish a web site on MEMS education with links to MEMS-education relevant sites elsewhere. The homepage for this workshop and its outcomes, as well as for shared materials from MEMS courses across North America, is maintained at: http://MEMSED.stanford.edu/

2. Encourage established MEMS conferences to incorporate MEMS education issues into the conference agendas

3. Consider holding regular workshops on MEMS education, embedded in larger conferences like the first one,

4. Address identity 'crisis' of MEMS versus Nano

5. Seek opportunities to integrate 'miniaturization' concepts and microscale examples into broader engineering education

6 . Work with industry groups on defining MEMS education standards and certificate programs

\section{ACKNOWLEDGMENTS}

The committee thanks the participants of the workshop for their time and enthusiasm and also the numerous survey participants who were unable to attend but found time to share their thoughts. The committee also thanks PMMI for smooth workshop registration and management. This work was supported by the National Science Foundation under grant ECS-0503895 and NASA Goddard Space Flight Center.

\section{REFERENCES}

[1] Survey data, MEMS Education Workshop, January (2005), Miami, FL. [2] ABET, Criteria for Accrediting Engineering Programs, Baltimore, MD.: Engineering Accreditation Commission, Nov. 11, 2003. See http://www.abet.org/criteria_eac.html.

[3] Ju, W. et al, "Project-Based Learning for Experimental Design Research," International Engineering and Product Design Education Conference, Delft, The Netherlands, 2004. 